This is an Accepted Manuscript of a book chapter published by Routledge/CRC Press in Mike Hulme (ed), Contemporary Climate Change Debates: A Student Primer on 11 December 2019, available online: https://www.routledge.com/Contemporary-Climate-ChangeDebates-A-Student-Primer-1st-Edition/Hulme/p/book/9781138333024.

\title{
Is Legal Adjudication Essential for Enforcing Ambitious Climate Change Policies?
}

YES: Because of the Inevitability and Significance of Legal Disputes about Climate Change

Eloise Scotford, Professor of Environmental Law, Faculty of Laws, Centre for Law and Environment, UCL

ORCID: 0000-0001-5216-5235

\begin{abstract}
Legal adjudication is inevitable and essential in enforcing ambitious climate change policies. This is because of the nature of climate change (it is controversial), because of the legal structure of the Paris Agreement (requiring nationally driven measures to pursue ambitious climate action), and because of the disputes that inevitably arise when widespread adjustment of polycentric social structures is required. Courts have an essential role in ensuring that climate policies are delivered in a fair and legally accountable way, in deciding inevitable legal disputes, and in expressing symbolic community statements relating to climate change.
\end{abstract}

\section{Introduction}

Legal adjudication is essential for enforcing ambitious climate policies, for two reasons. First, national courts have an inevitable role in our current international legal regime for responding to climate change. Second, the roles of courts and adjudication in legal systems represent essential functions in implementing and enforcing ambitious climate policies. 
The inevitable role of courts in enforcing climate change policies, particularly national courts, is driven by the nature of climate change and by the task now legally mandated to tackle this widespread social and environmental challenge through international law. Being a 'wicked' or 'hot' socio-political phenomenon, climate change is inherently disruptive of regulatory and legal systems. This gives the courts an inevitable role in adjudicating new legal questions and emerging social tensions that manifest through legal disputes (Fisher et al 2017). Further, the Paris Agreement puts legal action at the national scale squarely in the frame of climate policy. This is the scale at which the jurisdiction of courts - and access to them - is more routine, heightening the role for national courts in delivering ambitious climate policy under the Paris Agreement.

Not only is litigation concerning climate change is inevitable, but the roles played by courts in adjudicating disputes relating to climate policy are fundamental. First, at least in constitutional democracies, courts have a fundamental constitutional role in holding governments to account. Thus, when governments commit to national climate policies - in the form of nationally determined contributions (NDCs) under the Paris Agreement, or otherwise, such as through national climate policies or statutes - national courts will play a role in ensuring governments honour their commitments. This is enhanced by the structure of the Paris Agreement, which shifts accountability for Parties' climate policy commitments from international mechanisms (as under the Kyoto Protocol) to the national level.

Adjudicative processes themselves perform important roles in the climate change context. Courts must apply legal doctrines to legal disputes relating to climate policy that inevitably arise (their dispute resolution function), particularly where legal doctrines need to adapt or adjust to novel legal questions. Courts also give authoritative statements about those conflicts to the wider community (their symbolic function), and provide a lens for viewing the intricate social and economic implications of climate policy.

Two caveats or clarifications are important at the outset. First, there is no single type of legal dispute or court case relating to climate change. Cases can range from those that challenge national government climate policy generally, to those that concern the legal nature of rights created by regulatory schemes (such as an emissions trading scheme) or the determination of legal obligations when private individuals deal against the backdrop of climate policy. This essay defines 'climate change cases' broadly, covering any national 
adjudicative processes that relate to climate policy in some way. These cases will vary in subject matter and legal form. They will be covered by procedural and jurisdictional rules, and constitutional constraints, that are specific to the jurisdiction involved.

Second, in focusing on adjudication not litigation, the chapter's argument is focused on the role of courts and other adjudicative bodies (such as tribunals) rather than litigation strategies that interest groups or parties may seek to pursue. There is a thriving community of those involved in strategic climate litigation, but this is parasitic on the fundamental roles of courts and tribunals that apply and determine the law within legal systems.

\section{The 'Legally Disruptive Nature' of Climate Change: Climate Adjudication is Inevitable}

Climate change is legally disruptive. In a previously co-authored paper (Fisher et al 2017), we outlined four characteristics of climate change that make it disruptive in a legal sense: its causes and consequences are polycentric; the trajectory of climate change is scientifically uncertain; it inherently gives rise to socio-political conflict (both as a phenomenon and through ambitious policy efforts to address climate change); and it is a physically dynamic phenomenon. Each of these aspects of climate change creates difficulties for legal processes and doctrines that assume a stable natural environment and relatively stable relational and political structures in relation to which legal rights and obligations operate. The result of the 'wicked' social and environmental phenomenon of climate change is that legal disputes are inevitable. The law that applies to them will therefore not always be obvious, making adjudicative processes to determine the relevant law and to settle the positions of conflicting parties particularly important.

To exemplify this inevitability, let us consider ambitious climate policies that incentivise low carbon forms of energy supply by requiring transition away from existing energy production industries to low carbon industries of energy production. In any such energy transition, there will be winners and losers, and government policies will manage these changes more or less well. If poorly managed, legal disputes will arise and are proper avenues for those with grievances. Those industries forgoing revenue-making opportunities will have economic grievances and may seek legal recourse for impaired legal rights (e.g. they may bring claims for breach of contract, infringed constitutional rights, or review of government action on grounds of legitimate expectations or other public law grounds). New industry 
players may also have economic grievances that manifest in legal disputes (as in the case of government feed-in-tariffs that are quickly withdrawn due to oversupply). There might also be disappointed workers in high carbon emitting industries who lose jobs, or else citizens for whom energy costs rise quickly in an 'unjust' transition. Areas of law such as contract law, labour law and public law contain doctrines that will often be relevant in these kinds of circumstances. Even if well managed, major structural transition brings economic and social strain and legal arguments will arise. The economic, social and legal status quo is being unsettled by climate change, and legal claims express that disruption. These arguments must be settled for climate policy to be properly implemented.

As another example, let's say that a national government has adopted an ambitious national climate policy to achieve 'net zero' emissions of greenhouse gases by 2035 , setting out this mitigation goal in a widely publicised government policy document. There is however no 'climate change department' in this country's government and existing government departments continue working within their more siloed portfolios. In this particular country, the Department for Transport has been working on airport expansion plans for 10 years and determines that the issue of inadequate airport capacity is now urgent to resolve, recommending that the country's biggest airport be expanded. In its view, the government's flagship climate change commitment is not a barrier to this proposed airport expansion, as it does not require that any specific policy or development needs to change. In the department's view, climate policy innovation can come from somewhere else - after all, this new airport expansion policy is in the public interest.

Here we see a direct policy clash between climate and transport policy. This policy mismatch within the existing structures of government can be argued about politically but, ultimately, this is a question of accountability. The courts are the central organ of legal accountability in many jurisdictions and political systems globally and, in this example, would provide a key forum in which non-political actors can ask the government whether its airport expansion policy is rational. In the UK and in other jurisdictions, such judicial challenges to proposed airport expansions have, inevitably, been instigated (e.g. Friends of the Irish Environment CLG v Fingal County Council (2017) in Ireland concerning plans to expand Dublin's airport). 
These two examples each highlight how the radical change required by ambitious climate policies makes legal disputes inevitable. The large number of climate-related cases now being heard in courts around the world bears this out (Fisher et al 2017). These examples show how such disputes are essential - in determining where rights and liabilities lie as between private citizens, and in settling where public lines of accountability lie in governments.

\section{The Paris Agreement: Structuring National Climate Adjudication}

This inevitable pressure on national courts is enhanced by the structure of the Paris Agreement 2015. With its hybrid legal architecture - an international treaty relying on and constructed by nationally driven action - the Paris Agreement's obligations are to be determined at the national scale and implemented at the national scale. Granted there are international accountability mechanisms within the Agreement. In particular, there is Article 13 's non-punitive transparency mechanism to account for national action and support measures, subject to technical expert review, and Article 15's non-punitive, facilitative compliance mechanism involving the establishment and operation of an expert committee. But there is no formal enforcement mechanism at the international level for the national commitments made by signatory countries under the Agreement. Domestic legal action fills the compliance void, and is a critical forum for holding governments to account for their commitments under the Paris Agreement. This is supported by Article 4(2), which provides that 'Parties shall pursue domestic mitigation measures, with the aim of achieving the objectives [of successive NDCs]'. This is a mandatory requirement in the Paris Agreement (not all obligations in the Agreement are expressed in such mandatory language), indicating that legal enforcement is appropriate and necessary and must be situated at some level in the Agreement's hybrid governance structure.

In this vein, there has been a rise in the number of cases in different jurisdictions around the world since the 2016 ratification of the Paris Agreement, with various non-governmental organisations or groups bringing public law claims (tailored to jurisdictional contexts) against national governments in Party countries. These claims challenge various aspects of national government climate policy for not being sufficiently ambitious, when measured against the goals of the Paris Agreement and/or NDCs. At the time of writing, cases of this 
nature had been launched at least in the courts of the European Union, Germany, Ireland, and the United Kingdom.

The United Kingdom case in $R$ (Plan B and ors) v Secretary of State for Business, Energy and Industrial Strategy (2018) demonstrates how succeeding in these cases can be difficult (applying the relevant public law doctrines of a legal system). Nevertheless, their agitating and publicising impact can be considerable, providing a mechanism for indirect enforcement. In Plan B, the claimant NGO argued that the Secretary of State's refusal to revise the UK's 2050 carbon mitigaton target (set at that time in the Climate Change Act 2008 to require reduction of GHGs by $80 \%$ against 1990 levels) in light of the Paris Agreement meant that the UK Government was in breach of its international law obligations. The case was ultimately unsuccessful on the grounds that the government had not behaved irrationally and had a wide discretion in determining its climate policy. However, in the meantime, the Government referred a question to the national Committee on Climate Change asking it to reassess the UK's 2050 emissions target. The Committee reported back recommending that the target should indeed be revised to a 'net zero' target and, in June 2019, Prime Minister Theresa May announced on her final day in office that legislation had been laid before Parliament to revise the statutory target accordingly.

\section{The Role of Courts: Holding National Governments to Account for Climate Policy}

Even beyond the governance structure of the Paris Agreement, national courts play a fundamental role in holding their governments to account for executing the laws that have been enacted and in applying their own policies properly. Again, the constitutional and administrative law (that is, public law) frameworks for these legal accountabilities will vary in different jurisdictions. Some will have a formal written constitution against which public actions can be tested; some will have public law doctrines developed over time and applied by the courts (whether based in ideas of reasonableness, relevance of considerations taken into account, rationality, legitimate expectations, procedural fairness, proportionality, or other norms of good administration); and some will have codes or statutes that set out public law norms, which may include human rights (see Chapter 11). All these public law avenues are legal doctrines that embody and apply ideals of the rule of law - ensuring that those who govern us do so lawfully. The courts play an essential constitutional role in upholding these norms. 
Thus, again, it is unsurprising that public law actions of various forms have been brought to hold governments to account for their existing climate policies, or for pushing them to adopt more ambitious climate policies. Whether or not these actions are successful, this adjudicative function is essential for upholding the rule of law and good governance. And some actions have been successful. The Pakistani case of Ashgar Leghari v Federation of Pakistan (2015) is a well-known case where the Pakistan government was found to have been taking inadequate climate action on human rights grounds. The domestic Pakistan court issued quite interventionist remedies requiring the government to improve its administrative arrangements for implementing its own climate policy. A very well-known case brought against a government challenging its climate policy is Urgenda Foundation $v$ The Netherlands (2015). Many different legal arguments were made in this case brought against the Dutch government by an environmental NGO - based in human rights, the civil law doctrine of 'hazardous state negligence', and EU and international law - and most of them had legally novel aspects, whether on issues of legal procedure or liability. In both the lower District Court and on appeal in The Hague Court of Appeal, the state of The Netherlands was found to have adopted an unlawful national climate policy that was insufficiently ambitious in the short-term. In response to arguments that the court had overstepped its constitutional role in dictating government policy in deciding this case, the Court of Appeal was clear that the state is not above the law and needs to be held to account for any unlawful actions, particularly involving breaches of human rights (see Chapter 11). ${ }^{1}$

\section{The Role of Adjudication: Dispute Resolution and Symbolism}

In thinking about legal adjudication and climate change, it is easy to fall into the trap of thinking that adjudication is simply an instrumental route for compensation and justice. That is however a caricature of law and the role played by adjudication in courts and similar fora. Legal adjudication plays multiple roles, including (1) applying applicable laws and doctrines to legal disputes, and (2) performing a powerful symbolic function for

\footnotetext{
${ }^{1}$ At the time of writing (June 2019), Urgenda was heading for final appeal in the highest court of appeal in The Netherlands.
} 
communities bound by the rule of law. In relation to both these functions, legal adjudication is inevitable and essential in enforcing ambitious climate change policies. In terms of their dispute resolution function, courts are settling what the law is, whether in public law cases (as explained above) or in private law cases (where individuals, either people or companies, sue each other for some form of civil liability). This task can be straightforward but often involves novel legal reasoning due to the disruptive nature of climate change (Fisher et al 2017). Thus, in Urgenda, as indicated above, different legal arguments were successful at the different stages of the litigation, involving novel legal reasoning. For example, it was not clear whether the Urgenda Foundation (representing Dutch citizens but also citizens from other countries and future generations) should have standing. Standing doctrines are common issues of legal procedure, but there were novel facts to deal with in this climate context. Similarly, arguments of causation were novel. Why was the Dutch government being held accountable for its contribution to global climate change, which was relatively small and ultimately unconnected to any particular harm? The court adapted the test of causation to apply in this 'wicked' environmental context, acknowledging that applying existing tests of causation might mean that no country was responsible for climate change and its harmful consequences ('an effective legal remedy for a global problem as complex as this one would be lacking'). Whether courts will always adapt their legal procedures and doctrines to accommodate climate change in this way is subject to many factors and constraints of national legal culture, but ultimately a court needs to resolve the legal issue before it.

Resolving legal disputes between parties not only involves deciding and applying the law; it also sheds light on aspects of climate policy that might not otherwise be visible. The wide range of (sometimes quite technical) legal claims relating to climate policy demonstrates how the polycentric causes and implications of climate policy reach into very widespread spheres of social and economic life (see Chapter 12). For that reason again, climate adjudication - the settling of norms and rules in the intricate, every day, and widespread dealings of our societies and economies - is vital for delivering climate policy in a deep and socially transformative way (Bouwer 2018).

The second way in which climate adjudication is vital for enforcing ambitious climate policy is through its symbolic function. In articulating disputes concerning climate policy, in hearing 
them within the established and respected processes of the courts, in finding facts, and in establishing legal liability, courts send messages to their communities (local, national, global) in the cases that they hear and decide. In cases concerning climate change, where the socio-political backdrop can often be fraught, climate adjudication often has huge social significance and resonance (Fisher et al 2017). This can be demonstrated by the 2007 US case of Massachusetts $v E P A$, which essentially concerned an issue of statutory interpretation of the US Clean Air Act (whether air pollutants included greenhouse gases for the purposes of pollution regulation of vehicles). In the course of deciding the case, the Supreme Court stated that ' $[\mathrm{t}] \mathrm{he}$ harms associated with climate change are serious and well recognized.' The impact of this statement in a judgment of the US Supreme Court had huge symbolic significance, quite apart from the legal issue resolved in the case (Jasanoff). Climate change was a fact, and a serious issue, so said the court.

Similarly, the 2019 New South Wales Land \& Environment Court case of Gloucester Resources $v$ Minister for Planning - a planning appeal confirming that permission should not given to construct an open cut coal mine - had huge symbolic value, resonating globally as a ground-breaking climate case. In fact, resolving the planning appeal in the reasoning of the case did not turn on the climate impacts of the proposed mine, but the judge's careful consideration of climate change issues in the judgment was nonetheless seen as very significant.

Resolving climate-related legal disputes between parties also serves a symbolic function in a regulatory sense, due to the signalling function of decided cases. In private law claims in particular - for example, in contract, tort, or company law - the outcomes of these cases send signals about how businesses, individuals, and other actors should be acting in relation to climate change. For example, in company law and pensions law, claims might be made about whether companies or pension funds have properly taken into account climate change factors in applying the requirements of corporate reporting or pension investing. At the time of writing, these kinds of private law claims were being brought in Australia and considered elsewhere. The findings in such cases settle claims brought by individual shareholders or investors, but they also send a much wider message about how companies and pensions funds should operate in relation to climate change issues. These individualistic private law claims can provide a 'regulatory pathway' to delivering ambitious 
climate policy (Peel \& Osofsky 2017), and thus are an essential aspect of enforcing ambitious climate policies.

In adjudicating cases, there are facts to be agreed on and settled. There are disputes, concerns and inequalities that need to be afforded public and legal attention and that deserve the thoughtful consideration of respected adjudicative institutions in applying legal doctrines, irrespective of who wins the case ultimately. The outcomes of climate cases resolve legal disputes and are often highly symbolic for various interested communities, from concerned citizens, to companies operating against the backdrop of climate policy, to international parties sharing and observing national practices under the Paris Agreement.

\section{Conclusion}

The essential and inevitable nature of adjudication in enforcing ambitious climate policies does not mean that court actions or judgments alone will deliver ambitious climate policies. Far from it. It is fundamentally the architecture of a state's government and its administration that will deliver climate policies. However, courts have a critical role on holding that public action to account, and in confirming and expressing the obligations of myriad actors (public and private) in relation to the widespread social transition required by ambitious climate policies.

There is a risk that climate adjudication is misunderstood, or that it becomes the object of too many political hopes. Court cases are often seen as either wins or losses for climate policy. Judges can be incorrectly seen as saviours or untamed activists in the climate cause. These are misperceptions of the roles of courts and adjudication. This is not to deny that courts face challenges in applying legal principles and doctrines to disputes involving climate change, which are often legally disruptive due to the polycentric, socially contested, scientifically uncertain and dynamic nature of climate change. But the proper and fundamental roles of the courts should always be kept in mind. Courts must decide cases that come before them. They must declare what the law is. And they must hold governments to account. In doing so, they are often deciding very ordinary issues of legal doctrine or interpretation, albeit in a very complex context, which can make reasoning novel and challenging. Their job in adjudicating climate disputes is all the more important for that. 
Legal issues must be settled if climate policy is to be enforced, and, in the process, its full implications are rendered visible.

In the wake of ambitious climate policy, climate adjudication is inevitable and essential in societies subject to the rule of law.

\section{Reference list}

Kim Bouwer, 'The Unsexy Future of Climate Litigation' (2018) 30(3) Journal of Environmental Law 483

Elizabeth Fisher, Eloise Scotford \& Emily Barritt, 'The Legally Disruptive Nature of Climate Change' (2017) 80(2) Modern Law Review 173-201

Sheila Jasanoff, 'Serviciable Truths; Science for Action in Law and Policy' (2015) 93 Texas L Rev 1723, 1735

Jacqueline Peel and Hari Osofsky, Climate Change Litigation: Regulatory Pathways to Cleaner Energy (CUP 2015)

Massachusetts v EPA 549 US 497 (2007)

Airport expansion cases: $R$ (London Borough of Hillingdon) $v$ Secretary of State for Transport [2010] EWHC 626 (Admin); [Austrian case]; Friends of the Irish Environment CLG v Fingal County Council (2017)

Urgenda $v$ The Netherlands (The Hague District Court, 24 June 2015) ECLI:NL:RBDHA:2015:7196 (confirmed on appeal in The Hague Court of Appeal, 9 October 2018)

Ashgar Leghari v Federation of Pakistan (WP No 25501/2015), Lahore High Court Green Bench - note orders of 4 Sept and 14 Sept 2015

Plan B and ors v Secretary of State for Business, Energy and Industrial Strategy [2018] EWHC 1892 (Admin)

Gloucester Resources v Minister for Planning [2019] NSWLEC 7 (New South Wales Land and Environment Court) 


\section{Further Reading}

Sabin Centre, Climate Change Litigation Database, available at http://climatecasechart.com/ (accessed 10 June 2019). This is an extensive databases of court cases around the world involving climate change in some way. It divides the cases into public and private law claims, and provides summaries of the cases and links to court documents where available. You might reflect on what definition of 'climate change case' is used in compiling this database.

David Markell and JB Ruhl, 'An Empirical Assessment of Climate Change in the Courts: A New Jurisprudence or Business as Usual?' (2012) 64 Florida L Rev 15. This is an excellent article showing how difficult it can be to define a 'climate change case', even within a single jurisdiction (here the US). The authors argue that many of the US cases involving climate change (as defined by the authors, and which had been decided at the time of the article) involved courts applying the law as they usually would (and should), rather than breaking new legal ground.

Elizabeth Fisher, 'Climate Change Litigation, Obsession and Expertise: Reflecting on the Scholarly Response to Massachusetts v EPA' (2013) $39 \mathrm{~L}$ and Policy 236. This article reflects on why legal scholars have obsessed and become preoccupied with climate litigation in their research, focusing on writing about the high profile US Supreme Court case of Massachusetts v EPA. Fisher probes the different narratives at play when legal scholars are reflecting on climate litigation, and what legal expertise is implicated when they do so.

Joana Setzer \& Lisa Vanhala, 'Climate change litigation: A review of research on courts and litigants in climate governance' (2019) 10(3) WIREs Climate Change (advance access). This is a wide-reaching overview, from a political science perspective, of academic research concerning climate litigation and courts. It makes arguments about where there is scope for future research concerning the conditions under which litigation informs climate governance.

\section{Follow-up questions for use in student classes}


1. What is the function of law and adjudication in relation to climate change policy? (Or why does law matter?)

2. Who are most likely to be motivated to bring cases relating to climate change in the courts? (Think broadly!)

3. Who is most likely to have funding to bring climate cases in the courts?

4. What has been the most recent 'climate case' to capture global attention? Is this attention positive or negative, and is this justified? 